\title{
Formulaic Expressions of Politeness in Jordanian Arabic Social Interactions
}

\begin{abstract}
This study explores the use of politeness formulaic expressions in everyday social interaction in colloquial Jordanian Arabic. Analysis of ethnographically observed data of ninety-four formulaic expressions within the framework of Brown and Levinson's (1987) classical politeness theory reveals that these formulae are of two types: positive politeness formulae which are used in interactional and transactional contexts and emphasize solidarity and communal belonging; and negative politeness formulae concerned with showing deference and non-imposition. The use of these formulae reflects speakers' greater concern with positive rather than negative politeness. It further displays the fixity and continuity of social norms and traditions transmitted through these formulae. As many of these formulae involve reference to God, such formulaicity further emphasizes the religious and fatalistic nature of the community.
\end{abstract}

\section{Introduction}

This paper investigates formulaicity in colloquial Jordanian Arabic, specifically in the domain of everyday social interaction from the perspective of politeness theory. Although everyday spoken colloquial Jordanian Arabic is rich in formulaic expressions, these expressions have not received sufficient attention. This study, therefore, seeks to address and redress this gap by considering formulaic expressions as used in everyday social interactions in this variety of Arabic.

Formulaic expressions are exploited as 'conversational routines', defined by Coulmas (1981: 2) as "highly conventionalized prepatterned expressions whose occurrence is tied to more or less standardized communication situations". The formulaic expressions examined in this paper constitute "routine formulae" in line with Coulmas's (1994: 1292) definition, that is, they are 'fixed' both in form, compared to other expressions in the language which are created anew every time, and in function, in that they fulfil specific highly recurrent communicative tasks. They are conventionalized linguistic formulae triggered by specific communicative settings where their use is expected and deemed appropriate because they are seen as part of the speaker's communicative competence as well as

2 Open Access. () 2020 M. A. Badarneh, published by De Gruyter. (cc)BY This work is licensed under the Creative Commons Attribution 4.0 License. https://doi.org/10.1515/9783110669824-007 
his/her everyday politeness behavior. As Bardovi-Harlig (2012: 207) explains, formulaic expressions "often succinctly capture the illocutionary force of a contribution by virtue of the fact that the speech community in which they are used has tacitly agreed on their form, meaning, and use". According to her review of recent findings on formulaic language, definitions of formulaic expressions in pragmatics research usually contain three elements: they are recurrent sequences, they occur in specified social contexts, and they are known by members of a speech community (Bardovi-Harlig 2012: 207). These criteria will be shown to apply to the politeness formulae used in everyday Jordanian Arabic.

The meanings and uses of some formulaic expressions can be particularly appreciated when they are translated into English, showing the sociocultural specificity of Arabic as well as the values and beliefs of the speech community. While the use of these formulae is not obligatory, failure to use them in the appropriate context will result in socially negative conversational 'implicatures' (Grice 1975) and consequently constitute a threat to the interlocutor's 'positive face' or 'negative face' (Brown and Levinson 1987), which is another reason why these conversational formulae deserve attention.

Formulaic expressions are described as having a stereotyped, routinized, or fixed form; conventionalized meanings that include attitudinal and affective connotations; and specialized usage conditions (Hallin and Van Lancker Sidtis 2017: 69). The use and prevalence of such formulaic expressions in spoken discourse has been highlighted by different scholars (e.g. Coulmas 1981; Aijmer 1996; Kecskés 2003; Wray 2008; Bladas 2012). Formulaic expressions differ from newly created, grammatical utterances in that they are characterized by familiarity and predictability, are closely related to communicative-pragmatic context, and are widely regarded as crucial in determining the success of social interaction in many communicative aspects of daily life (Van Lancker Sidtis and Rallon 2004; Van Lancker Sidtis 2010). Native speakers can recognize and complete such formulaic expressions (when words are omitted) as well as demonstrate knowledge of their specialized meanings and appropriate contexts (Van Lancker Sidtis and Rallon 2004: 208). Tactical use of speech formulae is even honored in some languages, as reported by Tannen and Öztek (1981) regarding Turkish and Greek. This value and special status of formulaic expressions in social interaction has led to renewed interest in formulaic language as a large and vibrant part of language competence (Coulmas 1994; Kuiper 2004; Pawley 2007; Wray 2008), leading to increased interest in formulaicity in diverse discourse contexts, mainly as a result of the burgeoning interest in pragmatics, and the embracing of spoken text by sociolinguists and discourse analysts. The present study is carried out in 
the spirit of this interest and in light of the use of spoken discourse as an important source for investigating formulaic language and speech.

While formulaic expressions have been studied in different languages (e.g. Dogancay 1990; Takekuro 1999; Overstreet and Yule 2001; Terkourafi 2002; Saberi 2012; Levin 2014), they have not received as much attention in Arabic, and despite the prevalence of formulaic expressions in everyday Arabic social interactions, only a limited number of studies have investigated their communicative and pragmatic functions. A pioneering study in this area is Ferguson's (1983) work on the pragmatic features of what he called 'God-wishes' in Syrian Arabic, which are formulaic expressions that begin or are assumed to begin with 'God', and whose semantics is only peripherally related to their actual uses.

A number of studies have focused on the use of other God-related formulae that are originally religious expressions but have undergone pragmatic transformation, thus acquiring new discourse pragmatic functions in everyday Arabic speech, notably the two expressions that have an iconic status in spoken Arabic: inšallah (Gregory and Wehbe 1986; Farghal 1995; Clift and Helani 2010) and $m \bar{a} \check{s} \bar{a} a l l a h$ (Migdadi et al. 2010). These expressions are prototypically illustrative of a unique language feature that the Arabic language possesses, namely the socalled 'Allah Lexicon', which is a rich and varied body of religious expressions invoking the Almighty (Morrow 2006). Other researchers have analyzed broader and diverse aspects of Arabic formulaic expressions, such as their literary and textual sources (Müller 2000; Baccouche 2007), their use in relation to body parts in colloquial Arabic (Kotb 2002), their translation (Al-Qinai 2011), their transfer in cross-linguistic contexts (Ramajo Cuesta and Ainciburu 2015), and their sociolinguistic and pragmatic functions (Kamel 1993; Badarneh 2016).

The present study approaches Arabic formulaic expressions from a politeness theoretical perspective. It attempts to answer the following research questions:

- What role do Jordanian Arabic formulaic expressions play in social interaction in general and politeness in particular?

- What do these formulae tell us about the politeness orientation and face concerns of Jordanians?

- What do these formulae reveal about interactants' local sociocultural and religious values and assumptions? 


\section{Theoretical Framework}

The interpersonal meanings of formulaicity have been regarded as a discourse phenomenon because they can only manifest themselves within some concrete context (Norrick 2003: 86). Since such interpersonal meanings affect the alignment of conversational participants and their interpersonal relationships, the use of formulaic expressions as part of the poetics of everyday talk can be approached from the perspective of politeness behavior (Norrick 2003: 86). Relevant to this concern is the politeness theory of Brown and Levinson (1987) that is predicated on the sociological and highly abstract notion of 'face', derived from Goffman (1967) and from the English folk term linking face with embarrassment or humiliation. This 'face' is defined as "the public self-image that every member wants to claim for himself”, which makes face "emotionally invested" (Brown and Levinson 1987: 61). This concept of face consists of two aspects: positive and negative face. Positive face refers to participants' "perennial desire that [their] wants (or the actions/acquisitions/values resulting from them) should be thought of as desirable" (Brown and Levinson 1987: 101). Preserving the positive face of others would thus result in positive politeness, which involves the choice of strategies that emphasize solidarity with the addressee. These include claiming 'common ground' with the addressee and satisfying the addressee's wants (Brown and Levinson 1987: 101-129). Negative face refers to an individual's "want to have [their] freedom of action unhindered and [their] attention unimpeded" (Brown and Levinson 1987: 129). Maintaining this negative face of others would thus lead to negative politeness, which is linguistically realized through strategies that emphasize deference for the addressee, such as the use of conventional indirectness, hedges on illocutionary force, polite pessimism, e.g. about the success of a request, and emphasizing the relative power of the addressee (Brown and Levinson 1987: 130). Thus, negative politeness constitutes "rituals of avoidance" (Brown and Levinson 1987: 129) in polite interaction. In this theory, face is taken to be a universal notion in all human societies, and conversational participants are assumed to be rational agents who will ideally seek to preserve both their own face and their interlocutor's face in a verbal interaction. While stressing this universality of face, Brown and Levinson (1987: 13) recognize that in any particular society face can be "subject to cultural specifications" and naturally links up to "fundamental cultural ideas about the nature of the social persona, honor and virtue, shame and redemption and thus to religious concepts".

In such verbal interaction, different speech acts used by conversational participants intrinsically threaten face, such as criticisms, requests, and disagreements, referred to as 'face-threatening acts' (FTAs). A variety of FTAs can threaten 
the addressee's positive face, such as accusations, disagreements, and disapproval, while other FTAs can threaten the addressee's negative face, such as orders, advice, and warnings. A number of FTAs can be damaging to the speaker's own positive face, such as apologizing, while other FTAs can threaten the speaker's own negative face, such as accepting apologies. Given that both the speaker and the addressee seek normally to preserve face, an FTA that is damaging to the addressee's face will be also a potential threat to the speaker's face, and vice versa (Brown and Levinson 1987: 65-68). To minimize the threat of such FTAs, Brown and Levinson (1987) propose a set of strategies that are ordered along a continuum of remedial action, suggesting that the more threatening an FTA is, the more polite strategy one must use to reduce its damaging effects. In this case, the speaker uses a 'face-saving act' that involves either positive politeness redress or negative politeness redress, with negative politeness redress ranked higher than positive politeness redress. In contrast with negative politeness where "the sphere of relevant redress is restricted to the imposition itself, in positive politeness the sphere of redress is widened to the appreciation of alter's wants in general or to the expression of similarity between ego's and alter's wants" (Brown and Levinson 1987: 101).

Although Brown and Levinson (1987: 43) play down the importance of politeness routines by stressing the 'generative' production of linguistic politeness, they nonetheless state that polite formulae clearly form an important focal element in folk notions and in the distinction between 'personal' tact and 'positional' politeness, where the latter is associated with formulaic decorum (Coulmas 1979, 1981), of the type that is investigated in this paper.

This approach to linguistic politeness, which is pragmatic, is contrasted with a recent approach, described as post-pragmatic or 'discursive' (Watts 2003: 9), which constitutes a non-contextual paradigm of politeness and a complete departure from the static classical view of politeness adopted by Brown and Levinson (1987). This approach is based on a dynamic view of politeness, arguing that politeness is negotiated by the speaker and the hearer. Accordingly, politeness becomes discursive and negotiable, to the extent that "no linguistic expression can be taken to be inherently polite" (Locher and Watts 2005: 16), and hence politeness is theorized as the product of the evaluations of interactants in a particular speech event rather than assessment based on context. However, as argued by Schlund (2014: 5), this assumption may be suitable to a general theory of social practice, but it is not sufficient in linguistic terms because it does not provide a theoretical framework for the analysis of the structure of linguistic politeness devices, like the formulaic expressions examined here. Moreover, "the speakers of 
a given language would simply learn and thus know that certain linguistic politeness patterns stereotypically occur in certain speech situations" (Schlund 2014: 277).

\section{Data}

The data on which this paper is based consist of 94 formulaic expressions that were ethnographically observed in different everyday interactions in Jordanian Arabic. These formulae were collected by the researcher in naturally occurring interactions and exchanges involving native speakers of Jordanian Arabic. The observed interactions in which the formulaic expressions were used involved talk in a variety of conversational settings, such as interactions in supermarkets, grocery stores, restaurants, coffee shops, and shopping malls, interactions on private and public occasions, and interactions among family members, in-laws, friends, acquaintances, and strangers, which involved both interactional and transactional talk. The instances of formulae were checked against the researcher's own sociocultural background knowledge, expertise and repertoire as a native speaker and as a member of the community, as well as against the knowledge and expertise of other native-speaker community members who were consulted regarding the use and accuracy of each formula. All formulae collected were verified as authentic expressions that are recognized and used in actual social interaction. No formula displayed cross-functioning (Moon 1992: 21-22), that is, no formula was found to be "used with a function other than and additional to its primary one".

A number of the formulaic expressions collected behave like an 'adjacency pair' (Schegloff and Sacks 1973). That is, the formula becomes the first part of an automatic sequence where the utterance of the formula immediately creates an expectation of the utterance of a second part, i.e. a second formulaic response. In contrast, a number of formulaic expressions in the data do not create this expectation of a second-part formulaic response, and the addressee has thus the option to respond in a non-formulaic way. Given that these routine formulae are "situation-bound utterances" (Kecskés 2003), they are standardly taken to have a specific meaning and use in a specific context, beyond which they cannot be used. The occurrence of a formula, and thus its function, is therefore predetermined by a specific context that is communally agreed upon by the interactants.

It is important to point out that there are no corpora, electronic or otherwise, available for spoken Jordanian Arabic. This represents a methodological obstacle in the study and analysis of formulaic expressions and patterns in the spoken 
data of this Arabic variety. Ethnographical observation was chosen, therefore, to obtain the data. While this method has disadvantages such as time constraints, reliability, and access, it has a variety of advantages, especially direct observation of how the formulae are used, the ability to have a holistic view of these formulae, validity of the data as first-hand evidence, and being ecologically sound as the author is a member of the community where these formulae are used. Ethnographical observation would thus provide an effective method for the study of formulaic patterns in a given community as the researcher would better understand how such patterns are used in naturally occurring exchanges and be able to explicate the sociocultural meanings involved in their use.

\section{Analysis}

As stated above, each formula in Jordanian Arabic is situation-bound and context-specific. Accordingly, each formulaic expression was approached and analyzed according to the function it performs in the given (predetermined) communicative context. In addition to providing the predetermined context, the analysis of these formulae involved explicating their semantics, use and function, the typical response to the formula by the addressee, how the formulae reflect the sociocultural values and assumptions of the community at large, and the aspect of politeness with which these formulae are concerned, namely, positive or negative face of the speaker, the addressee, or both. Literal translations of these formulae are provided in order to capture their local sociocultural meanings and flavor, which are then explicated in more detail in the analysis.

The analysis of the data reveals that formulaic expressions used in Jordanian Arabic fall into two categories. The first category is oriented toward the positive face of the addressee or audience to communicate solidarity and common ground, and this category consists of two types: interactional formulae and transactional formulae. The second is concerned with the negative face of the addressee or audience to emphasize deference and non-imposition.

\subsection{Positive Politeness Formulae}

The great majority $(=76)$ of the formulaic expressions in the data $(80.9 \%)$ were found to be oriented toward positive politeness, which is in line with the observation that Arab societies tend to favor positive politeness (e.g. Davies 1987). For- 
mulae oriented toward the addressee's positive face are designed to communicate that the speaker and the addressee are familiar to one another. Thus, these formulae serve as an inclusive, in-group membership marker whereby the addressee is considered to be an insider treated as someone who belongs to the same community and shares the same sociocultural values. Positive politeness formulae in Jordanian Arabic attending to different aspects of the addressee's positive face can be categorized in terms of situational appropriateness into two types of contexts: interactional and transactional.

\subsubsection{Interactional Formulae}

Almost all formulaic expressions in the current data $(\mathrm{N}=91)$ are employed in primarily interactional (Brown and Yule 1983: 1) contexts, including social occasions involving festive and celebratory social bonding, such as public or private invitations to food on occasions such as weddings, graduation, house-warming, and child's birth invitations. In such interactional contexts, formulaic expressions are oriented toward focusing on the participants and their social needs, they are interactive, requiring two-way participation, and they reflect the participants' sociocultural and religious identity. Being interactionally oriented, these formulaic expressions can thus serve to "establish and maintain social relationships" and "negotiate role-relationships, peer-solidarity, the exchange of turns in a conversation, [and] the saving of face for both speaker and hearer" (Brown and Yule 1983: 3).

One of the domains where positive politeness formulaicity is exploited is hospitality, which is considered an inherent and hallowed ritualized tradition of Jordanian society (Shryock 2004: 35). Consider the following instances of hospitality-based formulae ${ }^{1}$ :

(1) Host: ahlan wa-sahlan

$$
\text { أَهْلاً وَنَهْلاُ }
$$

'Family and smooth land'

Guest: bi-l-mahlli

$$
\text { بِلْمْهَلَّيْ }
$$

'(Same) to one who says 'welcome”

(2) Host: nawwarat

$$
\text { نَوَرَتْْ }
$$

1 All translations are the author's unless otherwise indicated. 




(3) Guest: (Praises guest's food)

Host: $\quad$ şiћtayn $w^{-c} \bar{a}$ fiyeh

صِحْتِنْ وْعَافْيْة

'(May the food be) double health and healthiness (to you)'

Guest: $\quad{ }^{c}$ alā qalb-ak

عَلَى قَلْبَكْ

'(Same) to your heart'

(4) Host: (to someone shows up while one is eating): inţaћ fāl-ak

إنْطَحْ فَالَكْْ

'Hit your good omen'

Guest: $\quad$ (accepts or declines)

In (1), the speaker, i.e. the host, uses the traditional greeting formula ahlan wasahlan, typically functionally translated as 'welcome', and sometimes reinforced by wa-marhaban 'and hello', upon seeing the addressee, i.e. the guest. This formula is a prototypical politeness device in Arabic that is patently oriented toward the addressee's positive face, specifically his/her need to feel welcome upon being seen by the host. This can be further appreciated when considering the original expression from which the present formula derives, namely atayta ahlan wawaţi'ta sahl-an, which literally means 'You have come upon family and treaded on smooth land'. Thus the now shortened formula carries the meaning 'You are among people who are (like) your family and in a place that is hospitable to you'. The guest's one-word response bilmahlli 'same to one who says welcome' is equally formulaic and is designed to communicate equal positive politeness toward the host. Hospitality is thus formulaically shown to be central to the habitus (Bourdieu 1991: 37) of the local culture and its assumptions about the rights, needs and obligations of the host and the guest, and at the same time the importance attached to 'verbal generosity', combined of course with 'food generosity', toward one's guest or visitor is demonstrated.

In example (2), the host formulaically greets and welcomes the guest using the expression nawwarat. This formula metaphorically treats the guest as a source of 'light' that has eliminated 'darkness' in the host's home, which invokes the host's conceptualization and evaluation of the guest's visit and presence as highly desirable and conducive to joy. As nawwarat constitutes a compliment formula, the guest responds with another formulaic expression that is designed to 
reflect the guest's modesty and deflect the compliment by attributing such metaphorical 'light' to the host, that is, the owner and inhabitant of the house, which reduces the force of the compliment and shows the guest's appreciation of the host's invitation.

The health-wishing formula şihtayn $u^{c} \bar{a}$ fiyeh in (3) is invariably used to convey the speaker's wish that the food has a salubrious effect on the guest, typically after food is served. The fact that the formula consists of the dual şintayn 'literally, two healths' and reinforced by its synonym ' $\bar{a}$ fiyeh 'healthiness' reflects the formulaic aspect of home hospitality ritual, showing the strong emphasis placed on and the importance assigned to this ritual in the local culture. The guest's response 'ala qalbak 'lit. (same) to your heart' is equally formulaic and reflects the guest's similar health wish for the host. However, through metaphorical reference to the host's 'heart', the guest shifts the emphasis from his/her own physical health to the host's psychological well-being to reciprocate the host's positive politeness toward the guest.

Formulaicity thus iconically plays an important role in the realization of hospitality (and other traditions of the society). That is, the fixedness that comes with such hospitality formulae seems to reflect the permanence and endurance of this ritual in society, whereby these formulae are constantly reproducible in any context of hospitality. This can further be seen in example (4) where the formula inţa fālak 'literally, hit your good omen' is used as an invitation to someone who shows up unexpectedly while the speaker is eating. The words of the formula, and their literal meaning, reflect its Bedouin origin, taken to be the provenance of the tradition of Arab hospitality. More importantly, the metaphorical nature of the formula shows a concern with avoiding directness in inviting or asking an unexpected guest to join the host while eating. Through such metaphorical formulaicity, the host implies that the unexpected guest has not come for the sole or primary purpose of eating food, something that is very much avoided in local culture. It shows the speaker to be a competent community member who shows awareness of the addressee's face.

Another area where positive politeness formulaicity operates in everyday Jordanian Arabic is death-related discourse. While they show respect to the deceased, such 'death formulae' display solidarity with and provide solace to the audience affected, directly or indirectly, by the death event, such as family, relatives, and friends of the deceased (see e.g. Parvaresh and Capone 2017). While some of these formulae are inextricably linked to religious (i.e. Islamic) beliefs about death, other formulae constitute a colloquial form of prayer for the addressee or audience to live a longer life than the deceased, hence their positive politeness value in discourse: 
(5) Speaker: cađđama allāh-u ajra-kum

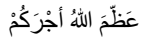

'May Allah increase your reward!'

Addressee: ̌akara allāh-u sac $a^{c}$ a-kum

شَكَرَ اللهُ سَعْيَكُمْ

'May Allah thank your efforts!'

(6) Speaker: yirham mā faqadit

يْرَحْمْ مَا فَقَّتِتْ

'May mercy be upon the one you lost!'

Addressee: $\quad m \bar{a}$ tufqud $\dot{g} a ̄ l i$

ما تُفْقُْْ غَالْيْ

'May you not lose a loved one!'

(7) Speaker: yislam rās-ak

\begin{tabular}{|c|c|}
\hline \multirow{4}{*}{ Addressee: } & 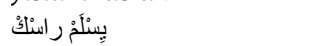 \\
\hline & 'May your head be safe!' \\
\hline & 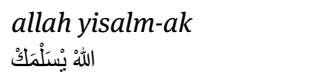 \\
\hline & 'May Allah keep you safe! \\
\hline
\end{tabular}

(8) Speaker: (Name of deceased) $a^{c} t \bar{a}-k^{c} u m r-u h /{ }^{c} u m r-h a$



'(The deceased) has given you his/her life'

As can be seen, in addition to reflecting sociocultural assumptions about death, these death formulae are adjacency pairs characterized by their reciprocal nature, where the use of one formula requires the obligatory use of a specific, fixed response. The formula in (5) is the formal Classical Arabic expression of offering condolences, still used today especially when the setting is public. It is purely religious as it involves a prayer to Allah to multiply the divine reward, or ajr, for the person affected by death in his/her family. This divine reward is believed to be given to the person who patiently endures, rather than expresses dissatisfaction with, the pain of losing someone. The addressee reciprocates by praying that the speaker be 'thanked' by Allah for their efforts of coming and offering condolences, so the act of thanking is metaphorically made by God rather than the speaker him/herself. Example (6) is a colloquial, and hence less formal, formula. It is predicated on the two concepts of 'loss' and 'mercy' where divine mercy is invoked upon the deceased, and where the second part is a prayer that the speaker will not go through similar loss of a loved one. 
The formulaic expression in (7) moves away from the divine and the religious toward a colloquial, socioculturally grounded mode of expression. More specifically, positive politeness toward the addressee is communicated metonymically by wishing that the addressee's 'head' be safe. The choice of this part of the body to refer to the person is motivated by the status of the 'head' in the Arab culture as a symbol of life itself (being alive). Focusing on these meanings shows how the formula is oriented toward the positive face of the addressee.

While the death formulae in (5-7) are solace-providing, the one in (8) is used when communicating a death event to someone. Rather than using a neutral term, e.g. twaffa 'passed away', the formula $a^{c} t \bar{a} k^{c}$ cumruh / 'umrha figuratively transforms the death of someone into an extended new life given to the bereaved or the news recipient, as if the lost life of the deceased will result in a longer life given to the news recipient. The formulaic transformation of death into a new life for the addressee thus becomes a positive politeness strategy, clearly implicating solidarity with the addressee and wishing that he/she lives a longer life. Such formulaicity in delivering news of death thus avoids mention of death terms, and at the same time offers emotional support to the recipient of the news of death.

Apart from the major discourses of hospitality and death above, formulaic expressions are employed as compliment speech acts in mundane everyday talk by way of orienting toward the addressee's or audience's positive face, as in the following examples:

(9) Speaker: naciman!

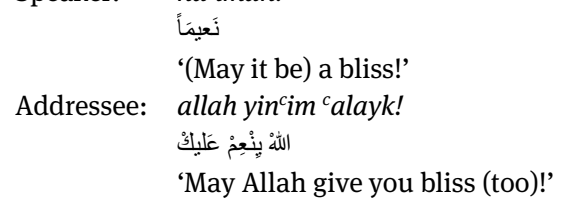

(10) Speaker: ̌arwa man cindi / šarwa il-ћāđrīn



'As praiseworthy as those sitting with me / As praiseworthy as the audience'

Addressee / wa-la t-hūn

Audience:

'May you not be belittled'

(11) Speaker: $\quad$ tihri $w$-tjaddid

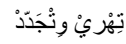

'May your clothes wear out and you renew them'

Addressee: $\quad$ tislam / $t^{c} \bar{\imath} \check{s} /$ w-ilgāyil

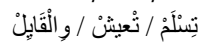


'(May you) be safe / (May you) live (a long life) / (Same to) the speaker’

In these examples, the formulae serve either as a compliment or a compliment response in a predetermined context. In (9), the formula na'iman! '(May it be) a bliss!' is used when meeting someone who has had a new haircut or has just taken a shower, and the absence of these formulae in these two contexts may be interpreted as a threat to the positive face of the referent in question. The formula šarwa man 'indi or its variant šarwa il-ћāđrīn 'As praiseworthy as you / as the audience' in (10) is an obligatory formula that must be used by the speaker when complimenting an absent third party in front of the addressee or audience. The formula is used to eliminate any suggestion or hint that the speaker is criticizing, underestimating, or negatively evaluating the addressee/audience by implicit comparison with that absent third party. Thus, the formula preemptively shows the speaker's awareness of the audience/addressee's positive face, communicating the implicature 'no critical comparison is intended' and 'you are equally good'.

The formula tihri $w$ tjaddid 'May your clothes wear out and you renew them' in example (11) is used as a compliment toward someone who has just bought new clothes. This compliment formula is not directed toward the new clothing item itself, but rather toward the person wearing it. By wishing that the addressee's new clothes wear out fast so that the addressee can buy yet more new clothes in the future, the formula expresses the wish that the addressee live a long life in which he/she can and will always buy and put on new clothes. This in turn implies that the speaker asks for constant renewal in the addressee's life, a renewal symbolized by the act of getting new items of clothing, so new clothes become a metaphor for renewal, i.e. prolonging, of the complimentee's life. The latter's understanding of 'prolonged and renewed life' is reflected in the three possible responses to the formula: tislam, which wishes the speaker safety and protection; $t^{c} \bar{\imath}$ š, which wishes the speaker a long life; and wilgāyil which is functionally similar to English 'right back at you', suggesting a more casual and easygoing tone. In these examples, the addressee shows agreement about praiseworthiness but with praise formulaically shifted back to the speaker in order to express common ground with, and mutual liking toward, the speaker.

\subsubsection{Transactional Formulae}

In contrast with interactional positive politeness formulae, only three formulaic expressions in the data were found to be used in transactional contexts that are intrinsically concerned with the transmission of information, e.g. price, rather 
than the maintenance of social relationships (Brown and Yule 1983). Brown and Levinson (1987: 103) insightfully argue that "positive politeness utterances are used as a kind of metaphorical extension of intimacy, to imply common ground or sharing of wants to a limited extent even between strangers who perceive themselves, for the purposes of the interaction, as somehow similar”. The transactional formulae discussed here are illustrative of this point. Through using such formulae, the speaker, i.e. the salesperson or shopkeeper, implies that, despite the business-oriented nature of the transactional talk, the salesperson still cares about the social dimension of the transactional relationship with the addressee, i.e. the customer. By using such formulae, the speaker will imply to the customer that the transaction is not purely materialistic or driven by mere financial gain, and that the salesperson is interested in establishing or maintaining a social relationship with the customer. This is illustrated by the following two commonly used transactional formulae:

(12) xalliha calayna

خَلَّيْهَا عَلْينًَا

'Make it on us'



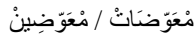

'May (what you paid) be compensated'

The formula in (12) is commonly used by a salesperson or shopkeeper when the customer hands over the money to pay for the goods or service. Although the formula is of course understood by the customer as an "ostensible speech act" (Link and Kreuz 2005: 227) of suggesting that the customer take the goods for free and therefore cannot be taken seriously, its use is widespread among shopkeepers, barbers, and local service providers in Jordan as a way of establishing or maintaining a social relationship with the customer, thus merely serving as a positive politeness gesture toward the customer. Realizing the nonserious and insincere (Isaacs and Clark 1990: 493-494) nature of this formula, the response of the customer would be, of course, something to the effect of šukran 'thank you'. The formula thus becomes a positive politeness technique used as a kind of 'social accelerator' whereby the speaker indicates that he/she wants to 'come closer' to the addressee (Brown and Levinson 1987: 103).

In contrast with (12), which is uttered before taking money from the customer,

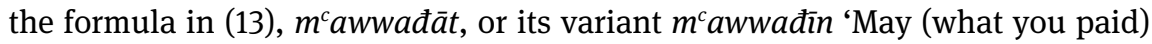
be compensated' is commonly uttered by the shopkeeper after the customer has paid for the goods. It is essentially an invocation (to God) that the customer may 
earn new money to replace the money he/she has just spent. While the speaker does not have to say this formula, uttering it will communicate that the speaker, even if not uttering the formula with total sincerity, at least sincerely wants to satisfy the customer's positive face (Brown and Levinson 1987: 101). Using the formula gives the transaction an interactional flavor and shows interest in the customer as a social actor rather than just a paying customer.

\subsection{Negative Politeness Formulae}

Formulaic expressions in everyday Jordanian Arabic constitute an important resource for satisfying the addressee's negative face wants by showing respect toward and non-imposition on the addressee or audience, and communicating the speaker's concern not to invade their private space. Although these negative politeness formulae constitute only $19.1 \%$ of the data collected (total 18), they cover different interactional aspects, as illustrated by (14-19) below:

(14) ba-la zuġrah



'Without smallness'

(15) w-inta b-karāmah

و إنْتَ بْكَر امَةْ

'And you are in dignity'

(16) w-inta l-kabir

و إنْتَ الكَبيرْ

'And you are the big one'

(17) w-inta l-şādig

و إنْتَ الصنّادِقْ

'And you are the truthful one'

(18) wa-la tac lim calayk

و لانَعليَّ عَليكَ

'And no teaching of you'

(19) harjak $^{c}$ ala rāsi

هَزْجَكْ عَلى راسني

'Your talk is on my head' 
As these formulae are addressed to negative face, they lie at "the heart of respect behavior" (Brown and Levinson 1987: 129). The formula bala zugrah in (14) is invoked when asking someone about his/her name or identity. The function of the formula is to minimize or eliminate the addressee's sense of being unknown or insignificant. That is, asking the addressee about their name or identity socioculturally communicates that the addressee is not known (hence zugrah 'smallness') in the community, so the formula serves to redress or eliminate that implicature.

The formula in (15) is called upon whenever a speaker mentions something that is socioculturally deemed offensive or evocative of unpleasant images. The mention of such a thing without using the hedging formula $w$-inta $b$-karāmah 'and you are in dignity' is considered an invasion of the listener's auditory space and hence a threat to their negative face, interestingly signified by the word karāmah 'dignity'. Examples of topics with which this formula must be used include mention of or reference to shoes, the toilet, feces, urine, and certain animals such as dogs, donkeys, and mules as these entities socioculturally symbolize, or are associated with, inferiority.

The formula $w$-inta l-kabir in (16) is used in a requesting context whereby the speaker (i.e. the requester) communicates to the requestee that the request made does not in any way mean or suggest that the requester has any power over, or has a higher status than, the requestee or that the requestee is under any obligation to comply with the request. In fact, the formula shifts a higher status onto the requestee ('you are the big one'), thus eliminating any sense of imposition upon, or intention of disrespect toward, the requestee. The appeal to kabir 'big' shows how the formula is used as a strategy for softening requests in a kinshipbased society like the Jordanian one (see Brown and Levinson 1987: 117-118) where there is a strong sense of social hierarchy.

The formula $w$-inta l-şādig 'and you are the truthful one' in (17) is employed in disagreement, an act typically seen as confrontational and are therefore dispreferred, and should therefore be mitigated or avoided (but see Sifianou 2012). The use of this formula stems from the need to minimize the face-threatening act of disagreement. Thus when the speaker disagrees with, contradicts, or corrects something that a participant has said, he/she softens such disagreement, contradiction or correction by formulaically communicating the message 'although what you said is inaccurate or incorrect, you are a truthful person and it is not my intention to accuse you of lying'.

The use of the formula wa-la tac lim ' alayk 'lit., and no teaching of you' in (18) constitutes a sociopragmatic norm in the specific context of giving of advice or making a suggestion (see DeCapua and Dunham 2007). In local Jordanian cul- 
ture, giving advice or instructing the addressee on how to perform a specific action or how to behave in a certain situation is considered highly face-threatening as it implies lack of knowledge or expertise on the part of the advisee. Therefore, this formula is used in such contexts as a preemptive strategy to deny any intention of arrogance or condescension on the part of the speaker. By using this formula, the speaker conveys that he/she is not assuming epistemological superiority over the addressee.

Finally, the formula harjak cala rāsi 'lit. 'your talk is on my head' in (19) is used in interruptions, often perceived as intrusive as they involve blocking of the flow of the current speaker's talk. This formula can be described as a meta-interruptive speech act whose use signals interruption of the current speaker, and as a palliative offered by the interrupter showing recognition that some infringement of the current speaker's rights has occurred. As the interruption is initiated, the formula is immediately invoked to communicate lack of intention to cause any threat to the current speaker's negative face, specifically the right to be heard and listened to. The formula is based on a metaphorical positioning of the current speaker's talk 'on the head' of the interrupting speaker where 'head' here symbolizes the highest degree of respect in Jordanian culture (cf. example 7). While the act of interruption occurs, the formula signals a preservation of negative face to communicate that no threat to the current speaker's autonomy and control over their talk turn is intended, thus making the act of interruption sound less disaffiliative and more affiliative.

\section{Conclusion}

The present chapter has provided a pragmatic account of the use of formulaic expressions in everyday Jordanian Arabic, grounded in the classical face-based politeness theory of Brown and Levinson (1987). These formulae constitute an integral part of everyday communication. They are so important because they are oriented towards preserving the participants' both positive and negative faces, thus ensuring the smooth flow of communication and adherence to fundamental sociopragmatic principles and rules.

Given the important and sensitive aspects of managing both the speaker's and the addressee's face in social interaction, the present study shows how formulaicity has come to play an important role in polite social interaction. As emphasized by Terkourafi (2002: 196), formulaic expressions "provide ready-made solutions to the complex and pertinent problem of constituting one's own and one's addressee's face while simultaneously ensuring that one's immediate goals 
in interaction are achieved". The use of Jordanian everyday formulae as discussed in this paper support the notion that formulaic expressions have an important role in the speaker effectively assuming the role of social actor as these formulae "embody accepted ways of responding verbally to a variety of situations" and therefore their use becomes "a strong indication of belonging, social identity or acculturation” (Coulmas 1994: 1293). As Terkourafi (2002: 196) maintains, this characteristic of formulaic speech makes it conducive to maintaining one's face through demonstrating familiarity with the norms of the community to which the speaker belongs. The present study thus supports the argument that formulaic speech carries the burden of polite discourse and the prediction that "the use of formulae may be a prominent feature of polite discourse in any culture", which needs "further quantitative studies of polite discourse across cultures" (Terkourafi 2002: 197). The present study has sought therefore to demonstrate this connection between formulaicity and politeness by examining formulae whose use is oriented towards preserving the participant's face in the underexplored language and culture of Jordanian society.

Formulaicity in social interaction as explored in this paper across specified, socially recognized and ratified communicative contexts suggests that such formulaicity reflects the fixedness of the norms and traditions of Jordanian society. This formulaicity further reflects the positive politeness leanings of Jordanians, as the majority of these formulae are oriented toward positive rather than negative face. Accordingly, through these formulae one can see more concern with solidarity and acquaintance, collectivist satisfaction, and communal belonging, as opposed to individualism and personal space.

\section{References}

Aijmer, Karin (1996): Conversational routines in English. London: Longman.

Al-Qinai, Jamal B. S. (2011): Translating phatic expressions. Pragmatics 21, 23-39.

Baccouche, Moufida Ghariani (2007): Arabic phraseology. In Harald Burger, Dmitrij Dobrovol'skij, Peter Kühn \& Neal R. Norrick (eds.), Phraseology: An international handbook of contemporary research, 752-759. Berlin, New York: De Gruyter.

Badarneh, Muhammad A. (2016): Proverbial rhetorical questions in colloquial Jordanian Arabic. Folia Linguistica 50 (1), 207-242.

Bardovi-Harlig, Kathleen (2012): Formulas, routines, and conventional expressions in pragmatics research. Annual Review of Applied Linguistics 32, 206-227.

Bladas, Òscar (2012): Conversational routines, formulaic language and subjectification. Journal of Pragmatics 44 (8), 929-957.

Bourdieu, Pierre (1991): Language and symbolic power. Cambridge: Polity Press. 
Brown, Gillian \& George Yule (1983): Discourse analysis. Cambridge: Cambridge University Press.

Brown, Penelope \& Stephen Levinson (1987): Politeness: Some universals in language usage. Cambridge: Cambridge University Press.

Clift, Rebecca \& Fadi Helani (2010): Inshallah: Religious invocations in Arabic topic transition. Language in Society 39 (3), 357-382.

Coulmas, Florian (1979): On the sociolinguistic relevance of routine formulae. Journal of Pragmatics 3 (3/4), 239-266.

Coulmas, Florian (1994): Formulaic language. In Ron Asher (ed.), Encyclopedia of language and linguistics, 1292-1293. Oxford: Pergamon.

Coulmas, Florian (ed.) (1981): Conversational routines. The Hague: Mouton.

Davies, Eirlys (1987): A contrastive approach to the analysis of politeness formulas. Applied Linguistics 8, 75-88.

DeCapua, Andrea \& Joan Findlay Dunham (2007): The pragmatics of advice giving: Cross-cultural perspectives. Intercultural Pragmatics 4-3, 319-342.

Dogancay, Seran (1990): Your eye is sparkling: Formulaic expressions and routines in Turkish. Penn Working Papers in Educational Linguistics 6 (2), 49-64.

Farghal, Mohammed (1995): The pragmatics of inšallah in Jordanian Arabic. Multilingua 14 (3), 253-270.

Ferguson, Charles (1983): God-wishes in Syrian Arabic. Mediterranean Language Review 1, 6583.

Goffman, Erving (1967): Interaction ritual: Essays on face to face interaction. New York: Garden City.

Gregory, Stanford Jr. \& Kessem Wehbe (1986): The contexts of inshaallah in Alexandria Arabic. Anthropological Linguistics 28 (1), 95-105.

Grice, Paul (1975): Logic and conversation. In Peter Cole \& Jerry L. Morgan (eds.), Speech acts, 41-58. New York: Academic Press.

Hallin, Anna Eva \& Diana Van Lancker Sidtis (2017): A closer look at formulaic language: Prosodic characteristics of Swedish proverbs. Applied Linguistics 38 (1), 68-89.

Isaacs, Ellen \& Herbert Clark (1990): Ostensible invitations. Language in Society 19, 493-509.

Kamel, Abdulaziz Mustafa (1993): A sociolinguistic analysis of formulaic expressions in Egyptian Arabic. Ph.D. thesis, Georgetown University.

Kecskés, István (2003): Situation-bound utterances in L1 and L2. Berlin: Mouton de Gruyter.

Kotb, Sigrun (2002): Körperteilbezogene Phraseologismen im Ägyptisch-Arabischen. 'Body part phraseology in Egyptian Arabic'. Wiesbaden: Reichert.

Kuiper, Koenraad (2004): Formulaic performance in conventionalised varieties of speech. In Norbert Schmitt (ed.), Formulaic sequences: Acquisition, processing, and use, 37-54. Amsterdam, Philadelphia: John Benjamins.

Levin, Magnus (2014): The Bathroom Formula: A corpus-based study of a speech act in American and British English. Journal of Pragmatics 64, 1-16.

Link, Kristen \& Roger Kreuz (2005): The comprehension of ostensible speech acts. Journal of Language and Social Psychology 24 (3), 227-251.

Locher, Miriam \& Richard Watts (2005): Politeness theory and relational work. Journal of Politeness Research 1 (1), 9-33.

Migdadi, Fathi, Muhammad A. Badarneh \& Kawakib Momani (2010): Divine will and its extensions: Communicative functions of maašaallah in colloquial Jordanian Arabic. Communication Monographs 77 (4), 480-499. 
Moon, Rosamund (1992): Textual aspects of fixed expressions in learners' dictionaries. In Pierre J. L. Arnaud \& Henri Béjoint (eds.), Vocabulary and applied linguistics, 13-27. Basingstoke: Macmillan.

Morrow, John (ed.) (2006): Arabic, Islam, and the Allah lexicon: How language shapes our conception of God. Lewiston, NY: Edwin Mellen Press.

Müller, Kathrin (2000): „Da war ihm, als müsse er fliegen vor Freude“: 'Tausendundeine Nacht' als Fundus für arabische Phraseologie. 'Thousand and One Nights as a source for Arabic phraseology'. München: C.H. Beck.

Norrick, Neal (2003): Discourse and semantics. In Deborah Schiffrin, Deborah Tannen \& Heide Hamilton (eds.), The handbook of discourse analysis, 76-99. London: Blackwell.

Overstreet, Maryann \& George Yule (2001): Formulaic disclaimers. Journal of Pragmatics 33, 45-60.

Parvaresh, Vahid \& Alessandro Capone (eds.) (2017): The pragmeme of accommodation: The case of interaction around the event of death. New York: Springer.

Pawley, Andrew (2007): Developments in the study of formulaic language since 1970: A personal view. In Paul Skandera (ed.), Phraseology and culture in English, 3-45. Berlin, New York: De Gruyter.

Ramajo Cuesta, Ana \& María Cecilia Ainciburu (2015): Transfer of Arabic formulaic courtesy expressions used by advanced Arab learners of Spanish. Procedia - Social and Behavioral Sciences 173, 207-213.

Saberi, Kourosh (2012): Routine politeness formulae in Persian: A socio-lexical analysis of greetings, leave-taking, apologizing, thanking and requesting. Ph.D. thesis, University of Canterbury.

Schegloff Emanuel \& Harvey Sacks (1973): Opening up closings. Semiotica 8, 289-327.

Schlund, Katrin (2014): On form and function of politeness formulae. Journal of Politeness Research 10 (2), 271-296.

Shryock, Andrew (2004): The new Jordanian hospitality: House, host, and guest in the culture of public display. Comparative Studies in Society and History 46 (1), 35-62.

Sifianou, Maria (2012): Disagreements, face and politeness. Journal of Pragmatics 44, $1554-$ 1564.

Takekuro, Makiko (1999): Formulaic speech and social conventions in linguistic politeness of Japanese. Paper presented at the International Symposium for Linguistic Politeness, Bangkok, 7-9 December 1999.

Tannen, Deborah \& Piyale Cömert Öztek (1981): Health to our mouths: Formulaic expressions in Turkish and Greek. In Florian Coulmas (ed.), Conversational routines, 37-54. The Hague: Mouton.

Terkourafi, Marina (2002): Politeness and formulaicity: Evidence from Cypriot Greek. Journal of Greek Linguistics 3, 179-201.

Van Lancker Sidtis, Diana \& Gail Rallon (2004): Tracking the incidence of formulaic expressions in everyday speech: Methods for classification and verification. Language \& Communication 24, 207-240.

Watts, Richard (2003): Politeness. Cambridge: Cambridge University Press.

Wray, Alison (2008): Formulaic language: Pushing the boundaries. Oxford: Oxford University Press. 